\section{ANIMALS ON PARADE}

The Story of Animal Life

By Dr. Maurice Burton. Vol. 1: The Framework of Animal Life; Invertebrates. Pp. xiit381. Vol. 2 : Vertebrates. Pp. viii +423 . (London: Elsevier Publishing Co., Ltd., 1949.) 63s.

TERE is a survey of the entire animal kingdom, 1 produced and illustrated in a luxurious fashion, and written mainly by Dr. Maurice Burton, deputy keeper of zoology in the British Museum (Natural History) and one of Britain's leading exponents of animal biology. Other zoologists contributed articles under the editorship of Dr. Burton. These include : Dr. W. E. Swinton, Mr. T. H. Savory, Dr. G. Crile, Dr. D. Dilwyn John, Prof. M. W. de Laubenfels, Dr. J. D. Ommaney, Dr. Ben Dawes, Dr. T. Mortensen, Dr. J. P. Harding, Dr. S. M. Manton, Dr. T. E. Snyder, Dr. C. H. Curran, Prof. G. D. Hale Carpenter, Dr. G. Barendrecht, Mr. G. Nixon, Prof. L. Bertin, Dr. C. M. Bogert, Mr. E. G. Turbott, Mr. D. Goodwin, Mr. B. East, Mr. K. W. Kenyon, Mi. W. Van Riper, Dr. W. R. Philipson, Dr. J. E. Hill, Mr. D. Fleay, Lotus and Margery Milne, Prof. W. H. Hodge, Mr. L. W. Walker, Mr. H. W. Nisson and Dr. Ida M. Mellen-an impressive list of names, but then this is an impressive work. The late Mr. W. P. Pycraft left a number of notes which the editor was able to utilize in the preparation of Vol. 2.

The two volumes are packed with photographs, most of them large ones, of a very high standard in art and animal portraiture. For example, the six pictures depicting commensalism and showing a hermit crab moving from one protective shell to another, to be followed soon afterwards by two sea anemones, are nothing short of superb. The close-up photograph of a praying mantis with a wasp gripped in its powerful fore-legs is an example of Nature photography at its best. There are more than a thousand such photographs, some of them full-page ; and both volumes are decorated with a few full-page colour-photographs. Some distribution maps are also included.

The text makes good reading since unnecessary technical terms are omitted, and, though there are many authors, Dr. Burton has done well in keeping the style flowing and consistent.

The subject material has an evolutionary background-the best method of approach in a survey of this kind. Classification, structure and, above all, behaviour, are closely studied. With this object in view, most of the many illustrations are of living animals in action. Having an evolutionary trend, the book must be based on the beginnings and framework of animal life. So there are chapters of the origin, mechanism, history, expression and background of life, followed by a survey of life in and under the sea. These chapters open up Vol. 1, and are followed by seventeen chapters on invertebrates, including seven on the insects. Vol. 2 deals with vertebrates, beginning with some of their forerunners, such as sea squirts and lancelets, etc. In this volume there are twenty-five chapters, seven of which are devoted to birds and eight to mammals. One chapter deals entirely with the psychology of apes. A final chapter is devoted to domesticated animals; but it is a pity that here the text is confined to animals domesticated in countries of the temperate regions, because the book itself deals with animals of the entire world.
This work can be strongly recommended. The very excellence of its ill strations and production in general will appeal to many categories of book. lovers. It is a valuable work of reference, having both systematic and subject indexes (though it is difficult to see why these should be in the reverse order in Vol. 2 compared with Vol. 1). Finally, all students of biology (especially degree students of zoology who have to spend so much of their time on comparative anatomy and not enough on animal behaviour, not to mention physiology) could not do better than get hold of these two volumes, for they are books to have as one's own.

Just a note for the publisher. Vol. 1 deals mainly with invertebrates. Why, therefore, use a photograph of a vertebrate (the lesser anteater, taken from Vol. 2) as the design of the book-jacket of Vol. 1, and another vertebrate (a bird) for the blind blocking on the front cover? Invertebrate motifs for the jacket and cover of Vol. 1 would render identification of the volumes easier, especially since the numbers and sub-titles appear only on the spine of each volume.

L. J. F. BrImble

\section{STATIC TRANSFORMERS AND SYNCHRONOUS ALTERNATORS}

Les machines électriques des réseaux

Par R. Langlois-Berthelot. Pp. 267. (Paris : Éditions Eyrolles, 1949.) 1700 francs.

THE main plant components of alternatingcurrent systems are alternators and transformers. These machines have been developed in the course of half a century to a remarkable degree of efficiency and reliability, as may be judged from the fact that. units exceeding $100,000 \mathrm{kVA}$. in capacity are beginning to be commonplace. Their working principles are familiar to all electrical engineers and to large numbers of radio amateurs, so that it may appear superfluous to take notice of another book about them. The main justification for doing so is the vast extent to which alternators and transformers are used in providing vital supplies of power and energy. More than one thousand alternators operate in parallel on the British grid system, and many more transformers of large capacity link the generating systems with the interconnecting network.

The transformers are exposed to two main hazards : over-stressing of insulation by lightning strokes to the overhead power lines, and mechanical stresses resulting from short-circuits on the system. The impulsive stresses due to lightning are of the order of 600,000 volts, and the mechanical stresses on shortcircuit can reach about a hundred times the normal full-load values. In addition, it is now customary to provide 'on-load' voltage-control equipment in the main transformers, so that they have lost their early simplicity and can justifiably be termed machines. Further complications may also be introduced for phase control, phase transformation, and to provide interconnexion between three or more systems in one unit. Current and voltage transformers used for supplying instruments and protective relays which are so commonplace at low voltages become the most expensive item of a power system per unit of useful output when the system voltage exceeds about 100,000 volts. The problem of finding a more economical method of supplying these small powers is 